\title{
Sexual dimorphism and geographic variance: their impact on the reliability of the antilingula as a landmark in human mandibular surgery
}

\author{
Milan Kapur ${ }^{1, *}$, Rahul Atul Shah ${ }^{1, *}$, Ashley Ferro $^{1}$, Shadi Basyuni ${ }^{1}$, Cecilia Brassett ${ }^{2}$, Vijay Santhanam ${ }^{3}$
}

${ }^{1}$ School of Clinical Medicine, University of Cambridge, CB2 OSP, United Kingdom

${ }^{2}$ Human Anatomy Teaching Group, Department of Physiology, Development \& Neuroscience, Downing Site, University of Cambridge, CB2 3DY, United Kingdom

${ }^{3}$ Department of Oral and Maxillofacial Surgery, Cambridge University Hospitals NHS Foundation Trust, Hills Road, Cambridge, CB2 0QQ, United Kingdom 


\section{ABSTRACT}

The intraoral vertical ramus osteotomy (IVRO) is an orthognathic procedure used to correct dentofacial abnormalities, performed by approaching the lateral aspect of the mandibular ramus. This approach precludes visualisation of the inferior alveolar nerve (IAN) on the medial side, thereby placing it at risk of iatrogenic damage. The antilingula, a bony prominence on the lateral mandibular ramus, has been proposed as a landmark for prediction of IAN location during IVRO. The current study aimed to evaluate variation in incidence and position of the antilingula, and therefore determine its suitability as a surgical landmark during IVRO.

This study included 480 dry hemimandibles from 8 geographic populations from the Duckworth Collection in Cambridge. Skulls were sexed by visual analysis of dimorphic traits. Positional relationships were determined through digitisation of 9 anatomical landmarks.

The antilingula was identified in all specimens. No significant difference was identified in the positional relationship between the antilingula and mandibular foramen between sexes. Multiple differences were identified in this relationship between geographic populations. Our data showed that, irrespective of geographical variation, an osteotomy performed $8 \mathrm{~mm}$ posterior to the antilingula would avoid the mandibular foramen in $98.8 \%$ of cases.

Keywords: Antilingula, IVRO, Mandibular foramen, Midwaist point 


\section{INTRODUCTION}

The intraoral vertical ramus osteotomy (IVRO) is a surgical procedure used in the correction of severe prognathism, an example of a class III malocclusion with abnormal protrusion of the mandible. This may lead to problems with mastication and speech, and contribute to temporomandibular joint dysfunction ${ }^{1}$.

During IVRO, the mandibular ramus is approached from its lateral aspect, and a vertical osteotomy is performed posterior to the presumed entry point of the IAN to the mandibular canal (Figure 1). This produces two mandibular segments that may either be fixed or, more usually, are placed in intermaxillary fixation (IMFS) for several weeks to allow for passive healing. Approach via the lateral mandibular ramus precludes direct visualisation of the entry point of the IAN into the mandibular foramen, in contrast to an alternative procedure such as the sagittal split osteotomy. In the absence of a reliable method to predict its location from lateral mandibular anatomy, IVRO places the IAN at significant risk of iatrogenic injury. 


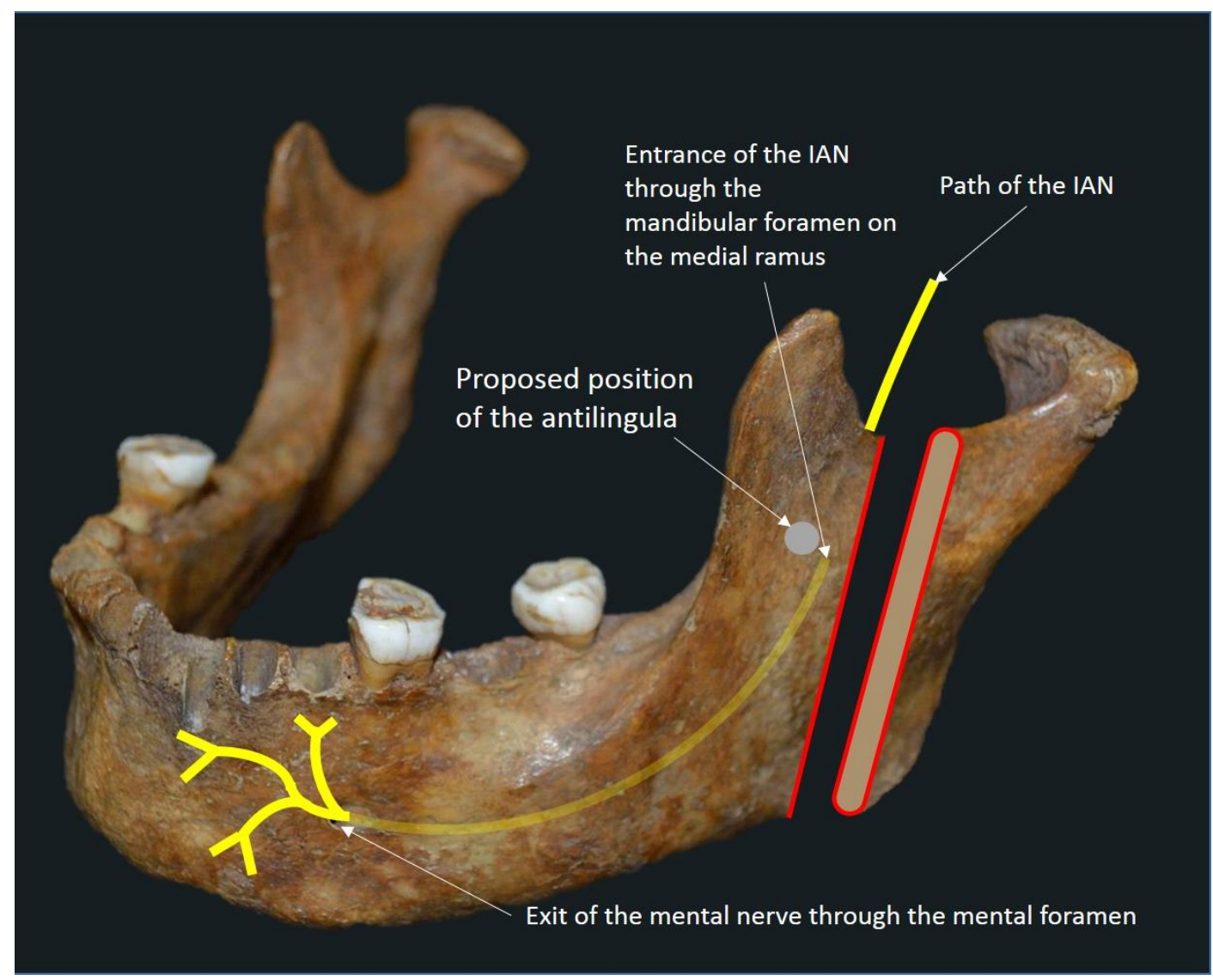

Figure 1. The intraoral vertical ramus osteotomy procedure. Red lines denote osteotomy surfaces.

Initially described by Caldwell and Letterman ${ }^{2}$, the antilingula, a bony prominence on the lateral aspect of the mandibular ramus, has been posited as a potential landmark that may be used to predict the location at which the IAN enters the mandibular canal medially. However, a number of difficulties exist regarding the use of the antilingula as a surgical landmark. Firstly, whilst its existence is not in doubt, there is considerable variability in the previously reported prevalence of the antilingula, with some authors ${ }^{3}$ identifying it in as few as $43 \%$ of cases and others ${ }^{4,5}$ reporting its presence in $100 \%$ of cases. Furthermore, in cases where it is present, there is much debate as to the precise anatomical relationships between the antilingula, mandibular foramen and lingula. Finally, geographic variation and sexual dimorphism in cranial anatomy is well recognized in the literature ${ }^{6}$, and may affect how the antilingula is applied as a surgical landmark in IVRO. The midwaist point, defined as the halfway point of the line joining the most concave 
points of the anterior and posterior curvatures of the ramus, has also been suggested as an alternative guide to the position of the IAN during IVRO ${ }^{3}$.

Although studies have previously evaluated anatomical variation of both the antilingula and midwaist point in the context of IVRO, these have been limited by small sample sizes, failure to consider sexual and geographic variation, and equivocal conclusions. Thus, there were two key objectives of this study. Firstly, to evaluate anatomical variation of the antilingula and midwaist point, thereby ascertaining their reliability in predicting IAN location - on the medial surface of the mandible. Secondly, given that cranial anatomy is known to vary with geographic origin and sex, we aimed to comprehensively investigate anatomical variation in the antilingula and midwaist point with respect to these two factors. Ascertaining the location of the antilingula relative to the mandibular foramen should allow definition of surgical safe zones during IVRO to prevent iatrogenic injury to the IAN irrespective of sex or geographic variation. 


\section{METHODS}

Adult human dry mandibles and skulls were selected from the Duckworth Collection in The Leverhulme Centre for Human Evolutionary Studies, Cambridge. Mandibles from the following locations were analysed for the study: Mainland Europe, England, New Zealand, New Britain, India, North America, South America and Africa. This study examined 480 hemimandibles from 267 mandibles, with 54 hemimandibles excluded due to trauma or significant deformity. Input from a Professor of Biological Anthropology was sought to ensure that only modern skulls were selected for measurement and analysis, thereby ameliorating influence of evolutionary bias.

Analysis of sexual dimorphism was performed exclusively on mandibles from the 'England' cohort, to ameliorate the potential influence of geographic location on mandibular morphology. Skulls were sexed using discriminant function analysis as outlined by Walker?

Nine landmarks (points) on each hemimandible were chosen for recording. Measurements were made using the MicroScribe ${ }^{\circledR}$ G2X Digitiser. This method records 3-dimensional coordinates of each chosen landmark relative to one another. Assuming the position of the hemimandible remains static, this essentially creates a virtual rendition of each hemimandible. The coordinates of each point were input into Microsoft Excel (2007) via the MicroScribe Utility Software version 6.0.s1. Definitions of selected points are listed in Supplementary Table 1. Two points were excluded due to fractures of the condylar head and coronoid process.

The horizontal and vertical displacements between the antilingula and lingula, antilingula and mandibular foramen, and the midwaist point and mandibular foramen were then calculated using the process outlined in the Appendix.

Inter-observer agreement was assessed between two independent observers using a mixed sample of 40 hemimandibles. The following six parameters were measured: the recorded vertical and horizontal distances from Point $A$ (the point of maximum concavity on the anterior border of the ramus) to the antilingula, lingula and mandibular foramen.

Bland Altman plots were used as a visual assessment of agreement (Supplementary Figure 1 ), and the intraclass correlation coefficient (ICC) was used as a quantitative proxy. 
Sexual dimorphism was determined by comparing the horizontal and vertical distances between points in male and female samples of the English cohort. Statistical analysis was performed using SPSS Statistics version 23. A $p$ value $<0.05$ was accepted as significant. 


\section{RESULTS}

Inter-observer Variability

In keeping with previous recognition that the antilingula is difficult to identify, the ICC values and Bland Altman plots support reduced inter-observer agreement of the antilingula location compared to other measured parameters (Supplementary Table 2). Overall inter-observer agreement was $0.723(95 \% \mathrm{Cl} 0.588,0.819)$ for measurement Aantilingula in the horizontal plane, and $0.46(95 \% \mathrm{Cl} 0.253,0627)$ for the same measurement in the vertical plane.

However, the mean difference between observers was $0.79 \mathrm{~mm}(\mathrm{SD}=1.37 \mathrm{~mm})$ for the horizontal distance and $1.47 \mathrm{~mm}(\mathrm{SD}=2.77 \mathrm{~mm})$ for the vertical distance. Given that the blade or drill width used for osteotomy is approximately $0.5-1 \mathrm{~mm}$, this discrepancy does not pose a clinically significant difference in inter-observer variability.

Antilingula and Lingula

The antilingula was identified in all 480 cases. The lingula was on average postero-superior to the antilingula with an average distance of $1.61 \mathrm{~mm}$ posterior $(\mathrm{SD}=2.75 \mathrm{~mm})$ and $0.64 \mathrm{~mm}$ superior ( $S D=4.61 \mathrm{~mm}$ ). The lingula was never found to be more than $11.1 \mathrm{~mm}$ posterior to the antilingula and was less than $8 \mathrm{~mm}$ posterior in $99.4 \%$ of cases (Figure 2 ). 


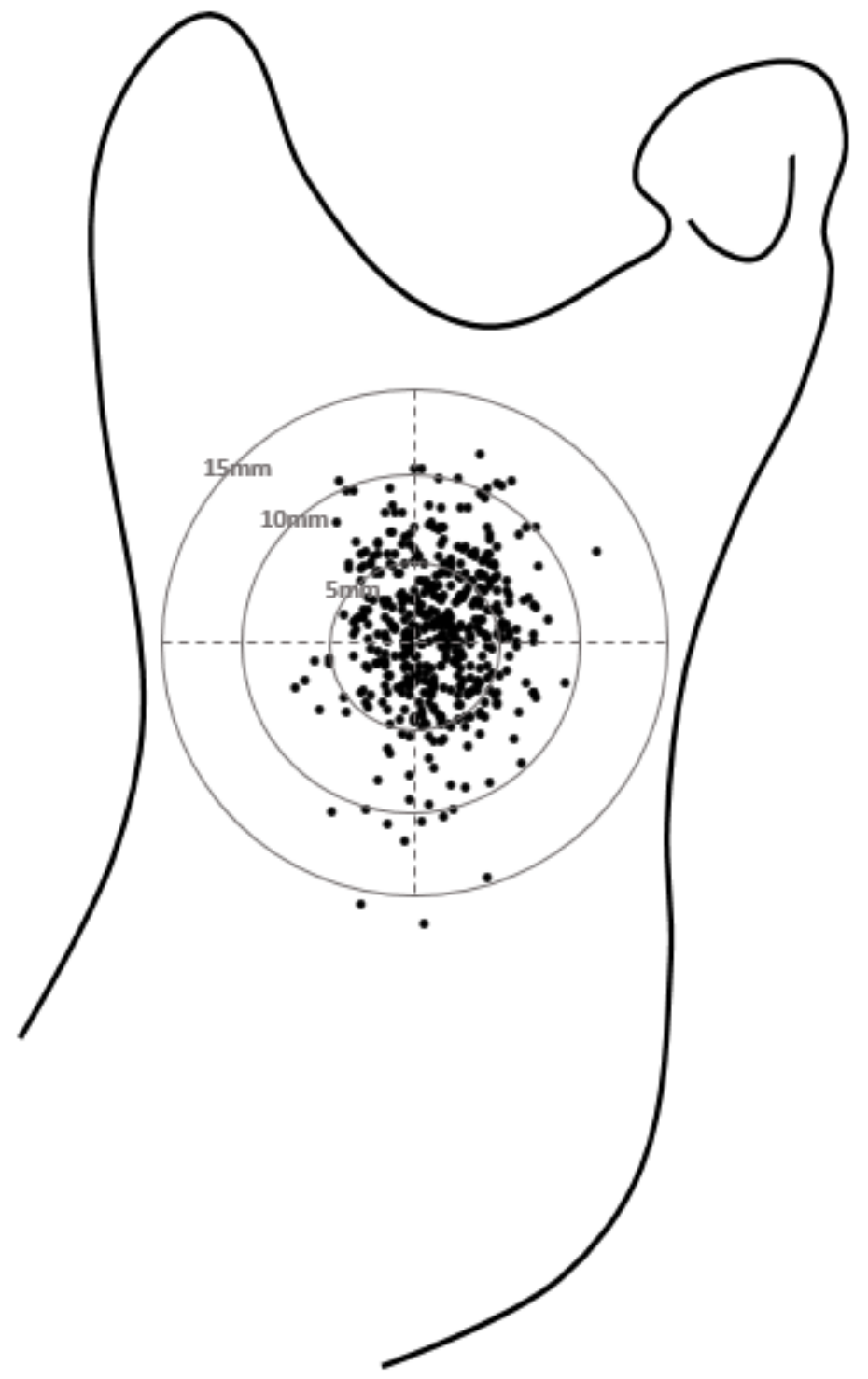

Figure 2. The position of the lingula relative to the antilingula (origin).

The horizontal distances between the antilingula and lingula in male and female samples were normally distributed (Shapiro-Wilk: $p=0.407,0.712$ ) and the assumption of homogeneity of variance was met (Levene's: $F=2.763, p=0.099)$. Independent Samples tTest reported no significant dimorphism in the horizontal distances $(\mathrm{t}(135)=1.734, p=$ $0.085)$. Data for the vertical distances were non-normally distributed in males (ShapiroWilk: $p=0.009$ ). Mann-Whitney $\cup$ Test also failed to detect significant dimorphism in the vertical distances $(U=2255, z=-0.303, p=0.762)$. 


\section{Antilingula and Mandibular Foramen}

The mandibular foramen was found to be postero-inferior to the antilingula with an average distance of $1.52 \mathrm{~mm}$ posterior $(S D=1.62 \mathrm{~mm}$ ) and $5.75 \mathrm{~mm}$ inferior $(S D=3.11 \mathrm{~mm})$. The mandibular foramen was less than $5 \mathrm{~mm}$ posterior to the antilingula in $90.4 \%$ of cases and less than $8 \mathrm{~mm}$ posterior in $98.8 \%$ of cases (Figure 3 ).

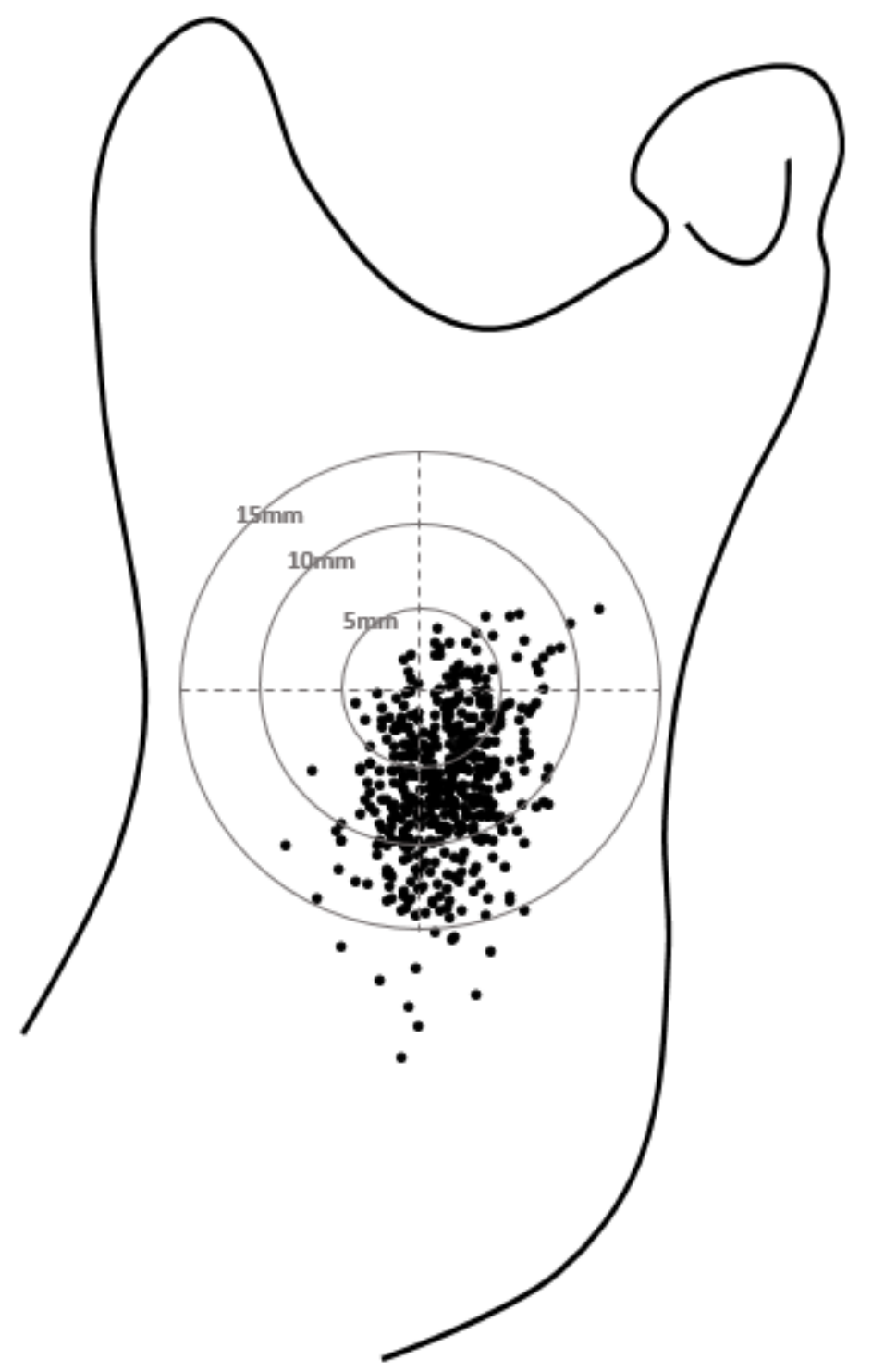

Figure 3. The position of the mandibular foramen relative to the antilingula (origin).

The horizontal distances between the antilingula and mandibular foramen in male and female samples were normally distributed (Shapiro-Wilk: $p=0.995,0.243$ ) and the assumption of homogeneity of variance was met (Levene's: $\mathrm{F}=0.953, p=0.331$ ). An 
Independent Samples t-Test reported no significant dimorphism in the horizontal distances $(t(135)=1.214, p=0.227)$. Data for the vertical distances were non-normally distributed in males (Shapiro-Wilk: $p=0.004$ ). Mann-Whitney $U$ Test also failed to detect significant dimorphism in the vertical distances $(U=2297, z=-0.121, p=0.904)$.

The data relating the relationship of the mandibular foramen to antilingula were not normally distributed across all groups (Supplementary Table 3). Subsequent nonparametric 'Independent Samples Kruskal-Wallis Test' revealed significant differences in the horizontal relationship between the antilingula and mandibular foramen across different geographic populations $(H(7)=20.533, p=0.05)$, as well as in the vertical relationship between these landmarks $(H(7)=21.454, p=0.03$ ). Post hoc analyses (Dunn's Test) found no significant differences between groups along the horizontal axis but found significant differences in two of the pairwise comparisons along the vertical axis (Table 1).

\begin{tabular}{lllllllll}
\hline Group & Europe & England & $\begin{array}{l}\text { New } \\
\text { Zealand }\end{array}$ & $\begin{array}{l}\text { New } \\
\text { Britain }\end{array}$ & India & $\begin{array}{l}\text { North } \\
\text { America }\end{array}$ & $\begin{array}{l}\text { South } \\
\text { America }\end{array}$ & Africa \\
\hline Europe & & 1.000 & 1.000 & 0.902 & 1.000 & 1.000 & 0.305 & 1.000 \\
England & 1.000 & & 0.698 & 0.549 & 1.000 & 1.000 & 0.152 & 1.000 \\
New Zealand & 1.000 & 1.000 & & 1.000 & 1.000 & 0.455 & 1.000 & 1.000 \\
New Britain & $\mathbf{0 . 0 4 1 ^ { * }}$ & 0.067 & $\mathbf{0 . 0 0 9 *}$ & & 1.000 & 0.390 & 1.000 & 1.000 \\
India & 1.000 & 1.000 & 1.000 & 0.057 & & 0.858 & 1.000 & 1.000 \\
$\begin{array}{l}\text { North } \\
\text { America }\end{array}$ & 1.000 & 1.000 & 1.000 & 0.075 & 1.000 & & 0.136 & 1.000 \\
$\begin{array}{l}\text { South } \\
\text { America }\end{array}$ & 1.000 & 1.000 & 1.000 & 1.000 & 1.000 & 1.000 & & 1.000 \\
Africa & 0.900 & 1.000 & 0.238 & 1.000 & 1.000 & 1.000 & 1.000 & \\
\hline
\end{tabular}

Table 1. Post hoc analysis of the horizontal relationship (blue) and vertical (red) between the mandibular foramen and the antilingula across different geographic groups. $P$ values quoted. Significant differences $(p<0.05)$ are indicated by asterisks.

\section{Midwaist Point and Mandibular Foramen}

Comparing the relative positions, the mandibular foramen was found to be located $1.63 \mathrm{~mm}$ posterior $(\mathrm{SD}=1.90 \mathrm{~mm})$ and $5.48 \mathrm{~mm}$ inferior $(\mathrm{SD}=3.37 \mathrm{~mm})$ to the midwaist point. There was considerable clustering, with the mandibular foramen lying posteroinferior to the midwaist point in $\mathbf{7 7 . 5 \%}$ of cases. The mandibular foramen was less than $5 \mathrm{~mm}$ posterior to the midwaist point in $95.6 \%$ of hemimandibles (Figure 4 ). 


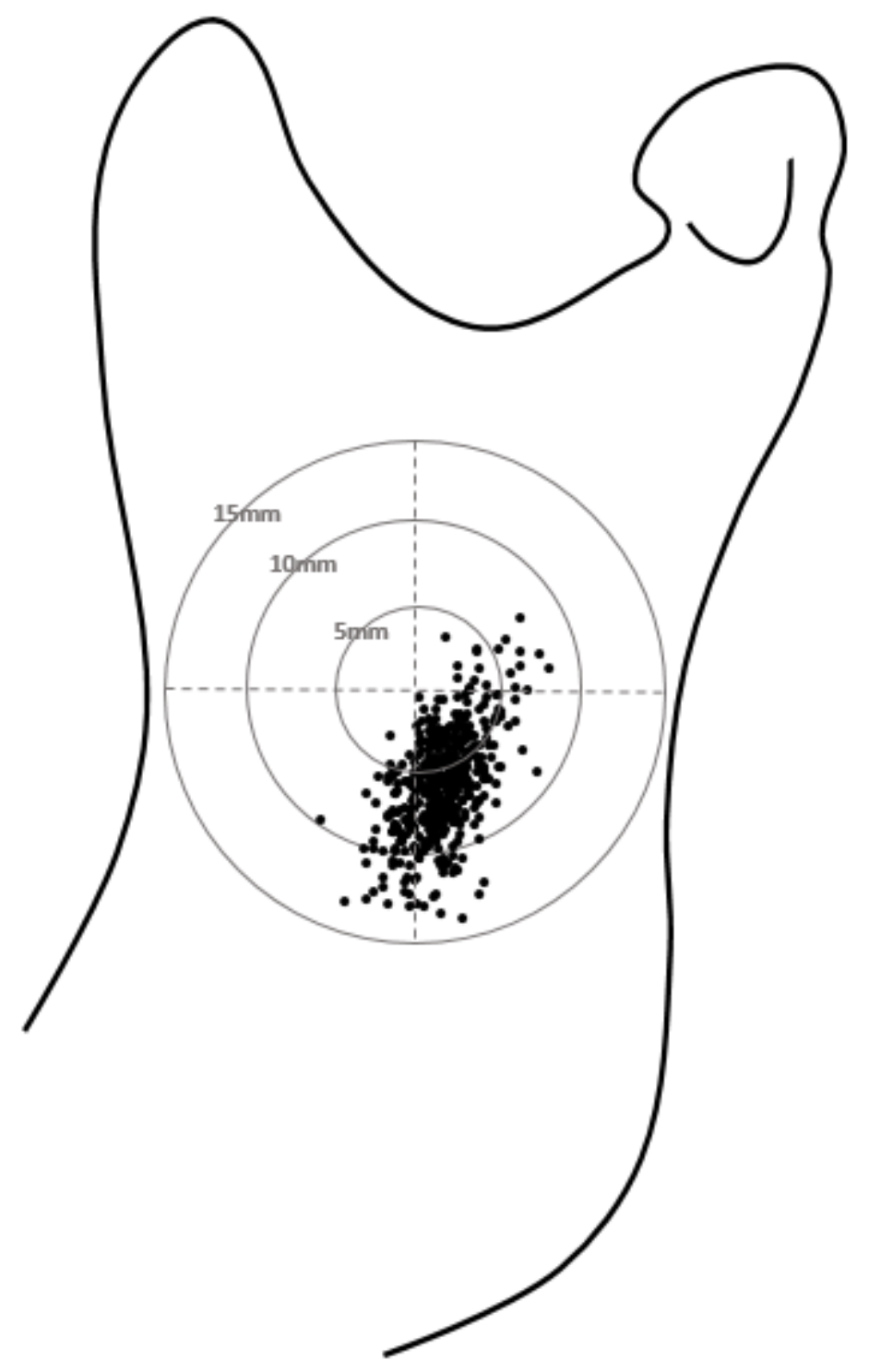

Figure 4. The position of the mandibular foramen relative to the midwaist point (origin).

The horizontal distances between the midwaist point and mandibular foramen in male and female samples were non-normally distributed (Shapiro-Wilk: $p=0.014,0.035$ ).

Mann-Whitney $U$ test reported significant differences in the horizontal distances between males and females $(U=1783, z=-2.344, p=0.019)$. On average, the mandibular foramen was $1.93 \mathrm{~mm}$ posterior to the midwaist point in males compared to only $1.12 \mathrm{~mm}$ posterior in females. The vertical distances between the midwaist point and mandibular foramen in 
male and female samples were normally distributed (Shapiro-Wilk: $p=0.057,0.845$ ) and the assumption of homogeneity of variance was met (Levene's: $\mathrm{F}=0.170, p=0.681$ ). The Independent Samples t-Test reported no significant dimorphism in the vertical distances $(\mathrm{t}(135)=1.755, p=0.081)$.

The data relating the relationship of the mandibular foramen to midwaist point were not normally distributed across all groups. An 'Independent Samples Kruskal-Wallis Test' failed to reveal significant differences in the horizontal relationship between the midwaist point and the mandibular foramen across different geographic groups $(H(7)=11.383, p=0.123)$, as well as in the vertical relationship between these landmarks $(H(7)=3.552, p=0.830)$. 


\section{DISCUSSION}

Mandibular osteotomy is a common procedure in facial deformity surgery. In cases of mandibular prognathism, the IVRO and the bilateral split sagittal osteotomy (BSSO) are most commonly performed ${ }^{8}$. During a BSSO, the medial surface of the ramus is exposed to enable visualisation of the IAN, thus reducing risk of nerve injury.

Additionally, rigid internal fixation can be used during BSSO instead of mandibulomaxillary fixation (MMF), enabling more rapid post- operative recovery and better airway management ${ }^{9}$. The BSSO, however, does not permit mandibular setback of more than $7-8 \mathrm{~mm}$, necessitating the utilisation of IVRO for more severe cases of prognathism ${ }^{9}$.

Regarding the relationship of the mandibular foramen relative to the antilingula, studies have reported either absence of correlation ${ }^{10-12}$, or that the mandibular foramen is situated posterosuperior to the antilingula ${ }^{13}$. The majority of studies, however, indicate the position of the lingula and mandibular foramen to be posteroinferior to the antilingula $3,5,14-16$. The vertical relationship between the antilingula and mandibular foramen appears to vary considerably, ranging from an average distance of $5.73 \mathrm{~mm}$ in our study, to $9 \mathrm{~mm}$ as reported by Chenna et al., ${ }^{16}$. The horizontal relationship, however, shows less variation, with $0.9 \mathrm{~mm}$ reported by $\mathrm{Yu}$ and Wong ${ }^{15}$, $1.5 \mathrm{~mm}$ reported by our study, and $1.6 \mathrm{~mm}$ by Chenna et al., ${ }^{16}$. As an IVRO is an incision along the vertical axis, this consistent horizontal relationship is key to determining the usefulness of the antilingula as a landmark to identify the IAN.

Previous investigations into the presence of sexual dimorphism have been limited by small sample sizes of 27 hemimandibles ${ }^{3}$ and 80 hemimandibles $^{15}$. This study had access to 137 sexed hemimandibles and found no evidence of sexual dimorphism in the position of the antilingula.

Previous studies have considered the relationship between the antilingula and the mandibular foramen in either a single ethnic group ${ }^{3}$ or in mandibles of unspecified ethnic origin ${ }^{17}$. This study had access to mandibles from 8 geographic regions, enabling a difference in the relationship between these points to be demonstrated across different ethnic groups. Geographic variation in skull morphology is well recognised and is thought to be primarily due to genetic drift ${ }^{18}$, although environmental selection pressures also contribute ${ }^{19}$. Considering mandibular morphology specifically, studies have previously determined that masticatory muscle 
force is associated with variation in mandibular bony morphology ${ }^{20}$. Hence, the difference across geographic populations identified may be due to the differing subsistence strategies in the populations, which may affect mandibular morphology ${ }^{21}$. This is well recognised in apes, whereby folivorous species (chiefly eating leaves) exhibit wider mandibular bodies than those with frugivorous diets (chiefly eating fruits), possibly due to the higher masticatory forces required for their $\operatorname{diet}^{22}$.

Regarding the relationship of the midwaist point to the mandibular foramen, previous authors suggested that the midwaist point had a reliable positional association to the mandibular foramen, and was therefore as accurate as the antilingula in predicting the position of the mandibular foramen ${ }^{3,11}$. Conversely another study, whilst finding a correlation between the midwaist point and mandibular foramen, did not find this landmark to be a consistent guide and therefore did not recommend its use as a landmark during ramus osteotomy ${ }^{23}$. In this study we found that one advantage of using the midwaist point was the apparent lack of variation in the relationship between the mandibular foramen and the midwaist point across different geographic populations. However, we do not recommend the use of the midwaist point over the antilingula, as not all mandibles had prominent posterior concavities and this reduced the accuracy of identifying the midwaist point, especially where ramus exposure may be limited intraoperatively.

Irrespective of any geographic variation, our data strongly suggest that an IVRO procedure undertaken $8 \mathrm{~mm}$ posterior to the antilingula would avoid the mandibular foramen, and hence the IAN, in $98.8 \%$ of cases (Figure 5). Given that the mean distance from the antilingula to the posterior concavity is $15.72 \mathrm{~mm}$, this recommendation would allow a proximal ramus segment of approximately $8 \mathrm{~mm}$ width, in concordance with the $7-8 \mathrm{~mm}$ suggested by McKenna and King ${ }^{24}$. As the proximal segment has to be plated to the distal segment after trimming, the proximal segment must be sufficiently wide for the insertion of screws.

In addition, this study found that an alternative approach may be to perform osteotomy $8 \mathrm{~mm}$ anterior to the posterior border of the ramus. This would avoid encroaching on the territory of the nerve in $99 \%$ of cases. This is in keeping with results from Park et al., ${ }^{25}$, who suggest a safe zone $9.02 \mathrm{~mm}$ anterior to the posterior border of the ramus, with our supporting conclusions based on a substantially larger 
data set. Despite the perceived reliability of this approach, analogous to the midwaist point, its clinical utility may be limited by variation in morphology of the posterior concavity and where there is limited intra-operative exposure of the mandibular ramus. However, it may be a useful contingency measure where the antilingula is challenging to identify intraoperatively.

Following IVRO, long-lasting neurosensory disturbance is demonstrated to be $4 \%{ }^{26}$. Thus, the ability to reliably identify the IAN through the use of the antilingula may be effective in reducing the incidence of nerve injury. Knowledge of the geographic and sex-based differences in this relationship will further aid the planning of an osteotomy.

As aptly demonstrated by the current study, the complex anatomy of the facial skeleton poses a significant challenge in operative planning. Careful consideration to bony landmarks, soft tissue architecture, neurovasculature and anatomical variation is fundamental to both achieving sound clinical outcomes and preventing iatrogenic injury. The emergence of virtual surgical planning, involving the fabrication of cutting templates and custom implants, reduces the emphasis on subjective assessment on the part of the surgeon on multiple operative factors, including plate positioning and position of bony cuts. This is particularly relevant in orthognathic surgery. As virtual surgical planning becomes increasing well established within the maxillofacial community, this inevitably reduces the emphasis on anatomical studies and the need to appreciate, to such an extent, anatomical variation in key surgical landmarks, given that the position of osteotomy is now pre-operatively determined. Despite this, in the pursuit of safe surgical practise, virtual surgical planning should not be considered an alternative to a complete understanding of key surgical landmarks, and the current study will be of benefit to the surgical trainee to aid appreciation of the complex nature of pre- and intra-operative planning and decision making.

\section{CONCLUSIONS}

The antilingula was identified in $100 \%$ of cases. There was no evidence of sexual dimorphism in the position of the antilingula. Whilst geographic variation in the position of the antilingula was observed, an osteotomy performed $8 \mathrm{~mm}$ posterior to the antilingula would avoid the mandibular foramen in $98.8 \%$ of cases regardless of geographic origin, thus making it a useful landmark to reduce the incidence of nerve injury. 


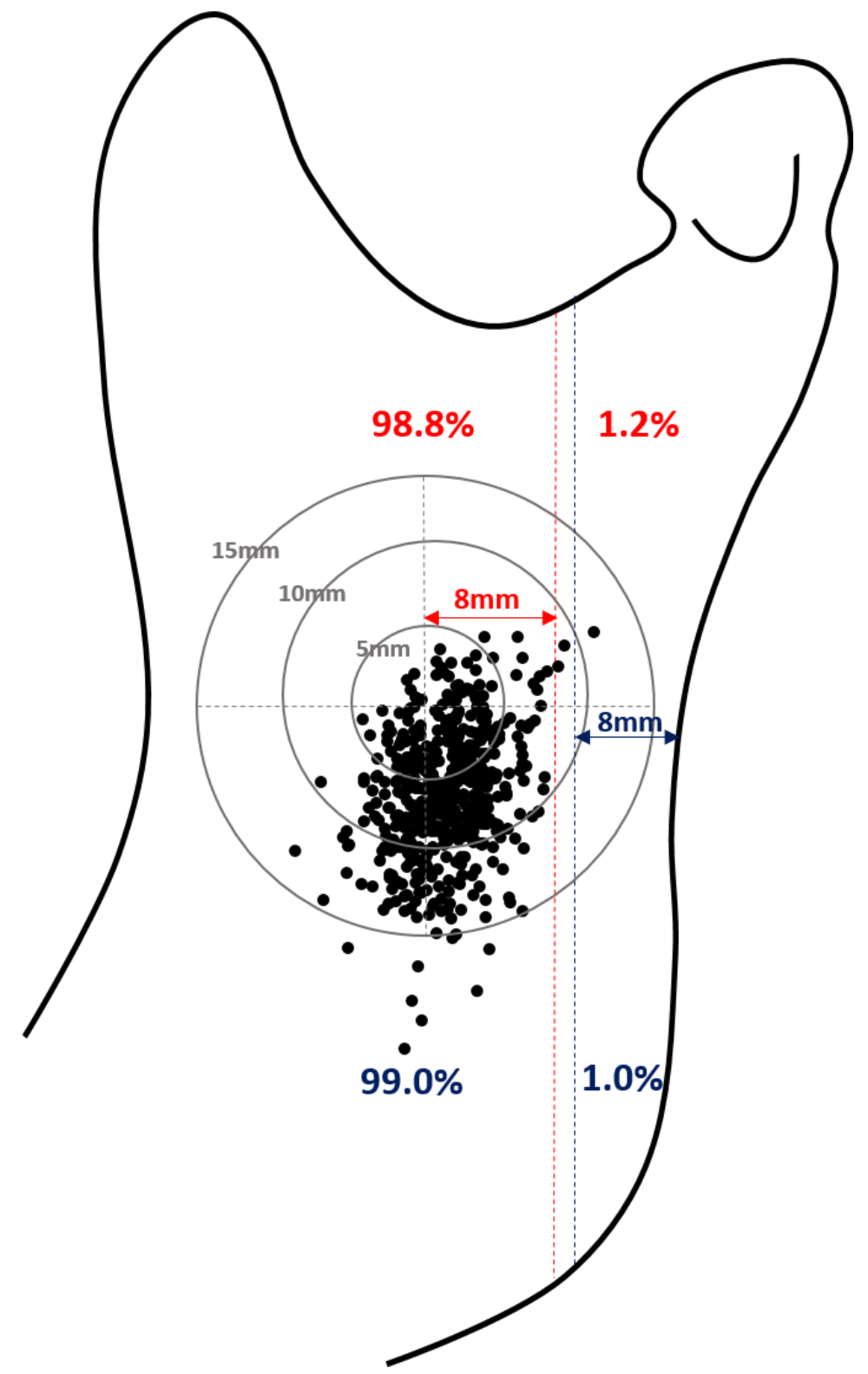

Figure 5. Proposed osteotomy sites denoted by the red line $(8 \mathrm{~mm}$ posterior to the antilingula) and blue line ( $8 \mathrm{~mm}$ anterior to the posterior border of the ramus). The centre of the concentric circles marks the position of the antilingula, relative to the mandibular foramen (plotted points), across all samples ( $n=480)$. Based on the relationship between the mandibular foramen and the antilingula, an osteotomy preserving $8 \mathrm{~mm}$ of bone posterior to the antilingula would avoid the IAN in $98.8 \%$ of cases. Additionally, an osteotomy $8 \mathrm{~mm}$ anterior to the posterior border of the mandibular ramus would avoid the IAN in $99 \%$ of cases. 


\section{CONFLICTS OF INTEREST}

The authors declare that there are no conflicts of interest regarding the publication of this paper.

\section{ETHICS STATEMENT/CONFIRMATION OF PATIENTS' PERMISSION}

Ethics approval was not required. Patients' permission not applicable.

\section{FINANCIAL DISCLOSURE STATEMENT}

The authors report no commercial or financial associations that might pose or create conflict with information presented in the manuscript.

\section{ACKNOWLEDGEMENTS}

The authors would like to thank Professor Marta Mirazon Lahr, Director of the Duckworth Laboratory, Leverhulme Centre for Human Evolutionary Studies, for her advice on experimental design and methodology. Additionally, we would like to thank Ms Emma Devereux at the Leverhulme Centre for her assistance with sample selection and handling, and Ms Fran Rivera at the Leverhulme Centre for her assistance in operating the MicroScribe ${ }^{\circledR}$ G2X Digitiser. Finally, we would like to thank the Statistics Clinic at the Centre for Mathematical Sciences, University of Cambridge, for advice on data analysis.

\section{REFERENCES}

1. Mladenović I, Dodić S, Stošić S, Petrović D, Cutović T, Kozomara R. TMD in class III patients referred for orthognathic surgery: psychological and dentition-related aspects. J Craniomaxillofac Surg. 2014 Dec;42(8):1604-9.

2. Caldwell JB, Letterman GS. Vertical osteotomy in the mandibular raml for correction of prognathism. Journal of Oral Surgery. 1954 Jul;12(3):185-202. 
3. Martone C, Ben-Josef A, Wolf S, Mintz S. Dimorphic study of surgical anatomic landmarks of the lateral ramus of the mandible. Oral surgery, oral medicine, and oral pathology. 1993;75(4):436-438.

4. Langston JR, Tebo HG. The incidence and relationship of the lateral ramus prominence to the mandibular foramen. Oral Surgery, Oral Medicine, and Oral Pathology. 1977 Aug;44(2):190-196.

5. Pogrel MA, Schmidt BL, Ammar A. The presence of the antilingula and its relationship to the true lingula. The British Journal of Oral \& Maxillofacial Surgery. 1995 Aug;33(4):235-238.

6. Ferro A, Basyuni S, Brassett C, Santhanam V. Study of anatomical variations of the zygomaticofacial foramen and calculation of reliable reference points for operation. British Journal of Oral and Maxillofacial Surgery. 2017 Dec 1;55(10):1035-41.

7. Walker PL. Sexing skulls using discriminant function analysis of visually assessed traits. American Journal of Physical Anthropology. 2008 May;136(1):39-50.

8. Yoshioka I, Khanal A, Tominaga K, Horie A, Furuta N, Fukuda J. Vertical ramus versus sagittal split osteotomies: comparison of stability after mandibular setback. J Oral Maxillofac Surg. 2008 Jun;66(6):1138-44.

9. Wolford LM. The sagittal split ramus osteotomy as the preferred treatment for mandibular prognathism. Journal of Oral and Maxillofacial Surgery. 2000 Mar;58(3):310-312.

10. Monnazzi MS, Passeri LA, Gabrielli MFR, Bolini PDA, de Carvalho WRS, da Costa Machado H. Anatomic study of the mandibular foramen, lingula and antilingula in dry mandibles, and its statistical relationship between the true lingula and the antilingula. International Journal of Oral and Maxillofacial Surgery. 2012 Jan;41(1):74-78.

11. Park K-R, Kim S-Y, Kim G-J, Park H-S, Jung Y-S. Anatomic study to determine a safe surgical reference point for mandibular ramus osteotomy. Journal of CranioMaxillofacial Surgery. 2014 Jan;42(1):22-27.

12. Lima FJC, Oliveira Neto OB, Barbosa FT, Sousa-Rodrigues CF. Location, shape and anatomic relations of the mandibular foramen and the mandibular lingula: $a$ contribution to surgical procedures in the ramus of the mandible. Oral Maxillofac Surg. 2016 Jun 1;20(2):177-82. 
13. Hosapatna M, Ankolekar VH, D'Souza AS, Deepika C, D'Souza A. The Study of Antilingula and Its Relation to the Lingula and Mandibular Foramen, the Presence of Mylohyoid Bridging in Dry Mandibles of South Indian Population. Journal of Maxillofacial \& Oral Surgery. 2015 Jun;14(2):308-311.

14. Yates $C$, Olson D, Guralnick $W$. The antilingula as an anatomic landmark in oral surgery. Oral Surgery, Oral Medicine, and Oral Pathology. 1976 Jun;41(6):705-708.

15. Yu IH, Wong YK. Evaluation of mandibular anatomy related to sagittal split ramus osteotomy using 3-dimensional computed tomography scan images. International Journal of Oral and Maxillofacial Surgery. 2008 Jun;37(6):521-528.

16. Chenna D, Hosapatna M, D'Souza AS, Gadicherla S, Pentapati KC. Lingula and Antilingula as Anatomic Reference Points for Ramus Osteotomies. International Journal of Dental Sciences and Research, International Journal of Dental Sciences and Research. 2014 Jan;3(1):1-3.

17. Aziz SR, Dorfman BJ, Ziccardi VB, Janal M. Accuracy of using the antilingula as a sole determinant of vertical ramus osteotomy position. Journal of Oral and Maxillofacial Surgery: Official Journal of the American Association of Oral and Maxillofacial Surgeons. 2007 May;65(5):859-862.

18. Relethford JH. Population-specific deviations of global human craniometric variation from a neutral model. American Journal of Physical Anthropology. 2010;142(1):10511.

19. Roseman CC, Weaver TD. Multivariate apportionment of global human craniometric diversity. Am J Phys Anthropol. 2004 Nov;125(3):257-63.

20. Sella-Tunis T, Pokhojaev A, Sarig R, O’Higgins $P$, May H. Human mandibular shape is associated with masticatory muscle force. Sci Rep. 2018 Apr 16;8(1):1-10.

21. Cramon-Taubadel N von. Global human mandibular variation reflects differences in agricultural and hunter-gatherer subsistence strategies. PNAS. $2011 \mathrm{Dec}$ 6;108(49):19546-51.

22. Taylor AB. Diet and Mandibular Morphology in African Apes. Int J Primatol. 2006 Apr 19;27(1):181.

23. Apinhasmit W, Chompoopong S, Jansisyanont $\mathrm{P}$, Supachutikul K, Rattanathamsakul N, Ruangves $S$, et al. The study of position of antilingula, midwaist of mandibular ramus and midpoint between coronoid process and gonion in relation to lingula of 92 Thai 
dried mandibles as potential surgical landmarks for vertical ramus osteotomy. Surgical and radiologic anatomy: SRA. 2011 May;33(4):337-343.

24. McKenna SJ, King EE. Intraoral Vertical Ramus Osteotomy Procedure and Technique. Atlas Oral Maxillofac Surg Clin North Am. 2016 Mar;24(1):37-43.

25. Park JH, Jung H-D, Kim HJ, Jung Y-S. Anatomical study of the location of the antilingula, lingula, and mandibular foramen for vertical ramus osteotomy. Maxillofac Plast Reconstr Surg [Internet]. 2018 Jul 25 [cited 2019 Oct 26];40(1). Available from: https://www.ncbi.nlm.nih.gov/pmc/articles/PMC6057865/

26. Al-Bishri A, Barghash Z, Rosenquist J, Sunzel B. Neurosensory disturbance after sagittal split and intraoral vertical ramus osteotomy: as reported in questionnaires and patients' records. International Journal of Oral and Maxillofacial Surgery. 2005 May 1;34(3):247-51. 


\begin{tabular}{ll}
\hline Point measured & Definition \\
\hline Condylar head & Most infero-lateral aspect of the condylar head \\
Coronoid process & Tip of the coronoid process \\
Sigmoid notch & Most inferior point of the sigmoid notch \\
Antilingula & Most supero-lateral aspect of ramus \\
Posterior border of ramus & Most concave point of posterior curvature \\
Anterior border of ramus & Most concave point of anterior curvature \\
Angle of mandible & Most postero-inferior aspect of ramus \\
Lingula & Tip of the lingula \\
Mandibular foramen & Most infero-medial point of mandibular foramen \\
\hline
\end{tabular}

Supplementary Table 1

Measurement

Mean difference (mm)

ICC estimate

Point A-AL Horizontal Distance

0.79

0.723

Point A-AL Vertical Distance

1.47

0.46

Point A-L Horizontal Distance

0.37

0.954

Point A-L Vertical Distance

0.88

0.665

Point A-MF Horizontal Distance

0.47

0.921

Point A-MF Vertical Distance

0.87

0.782

\section{Supplementary Table 2}

\begin{tabular}{|c|c|c|c|c|c|c|}
\hline \multirow[b]{2}{*}{$\begin{array}{l}\text { Geographic } \\
\text { origin }\end{array}$} & \multicolumn{3}{|c|}{$\begin{array}{l}\text { Shapiro-Wilk: Horizontal relationship } \\
\text { of antilingula to lingula }\end{array}$} & \multicolumn{3}{|c|}{$\begin{array}{l}\text { Shapiro-Wilk: Vertical relationship } \\
\text { of antilingula to lingula }\end{array}$} \\
\hline & Statistic & $d f$ & Sig. & Statistic & $d f$ & Sig. \\
\hline Africa & 0.979 & 42 & 0.628 & 0.989 & 42 & 0.950 \\
\hline
\end{tabular}




\begin{tabular}{lcccccc} 
England & 0.994 & 183 & 0.636 & 0.986 & 183 & 0.072 \\
Europe & 0.971 & 53 & 0.215 & 0.970 & 53 & 0.195 \\
India & 0.981 & 48 & 0.608 & 0.979 & 48 & 0.557 \\
New Britain & 0.983 & 43 & 0.749 & 0.945 & 43 & 0.041 \\
New Zealand & 0.969 & 40 & 0.347 & 0.971 & 40 & 0.382 \\
North America & 0.979 & 32 & 0.781 & 0.974 & 32 & 0.622 \\
South America & 0.946 & 37 & 0.071 & 0.951 & 37 & 0.105 \\
\hline
\end{tabular}

Supplementary Table 3. Shapiro-Wilk results of the horizontal and vertical relationships of the antilingula to the lingula. 


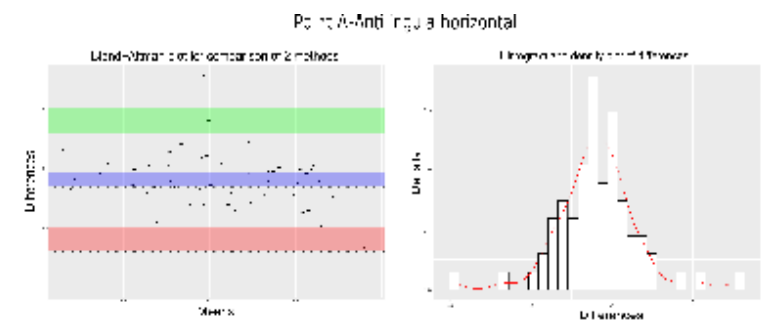

Supplementary Figure 1
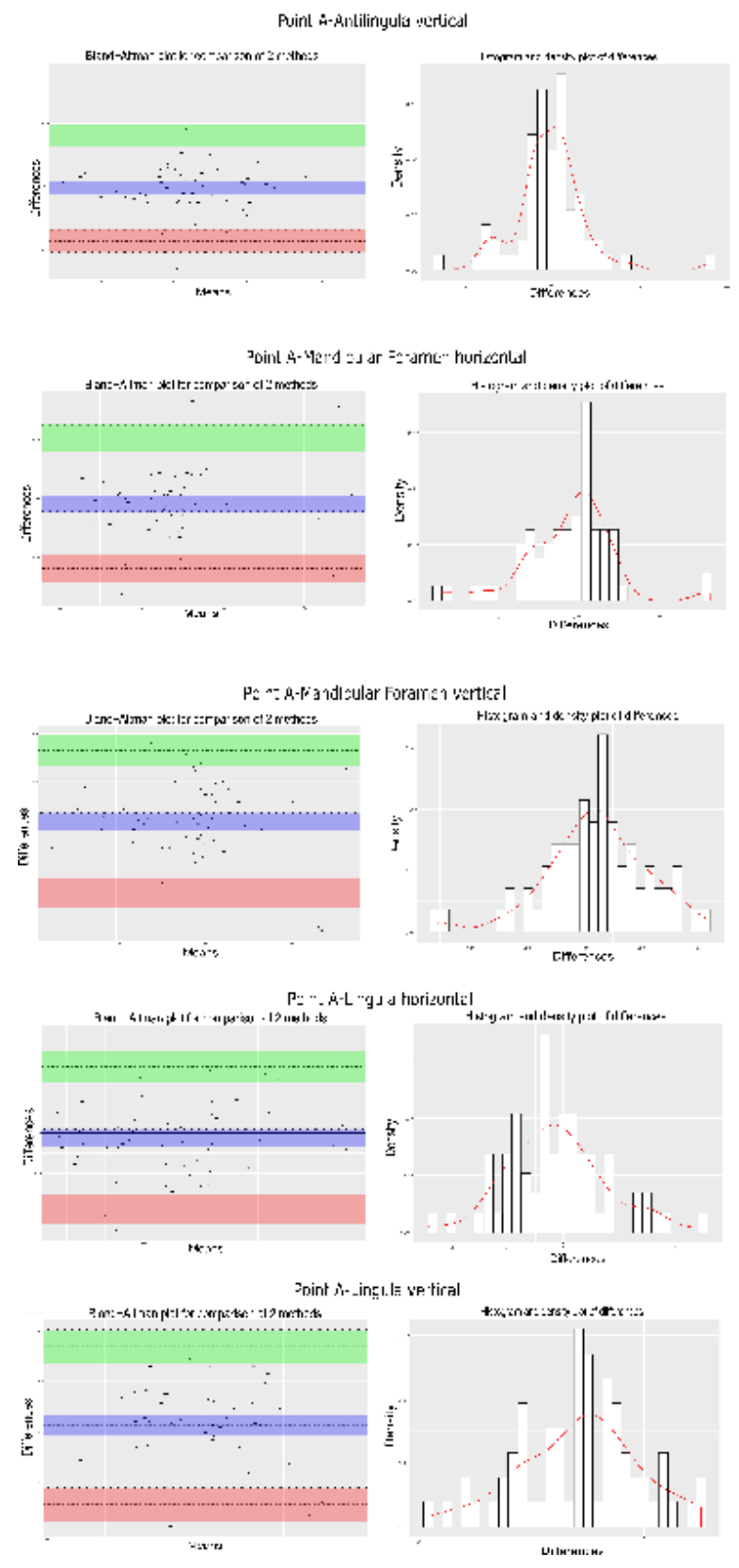


\section{APPENDIX}

The 3D coordinate outputs of the MicroScribe were subsequently processed into the relevant 2-dimensional horizontal (antero-posterior) and vertical (supero-inferior) relative distances using the following method:

First, four points are defined:

- $\quad P$ - the point representing the Posterior Curvature.

- $A$ - the point representing the Anterior Curvature.

- $S$ - the point representing the Sigmoid Notch.

- $O$ - an arbitrary origin.

Then, two 3D vectors ( $\mathbf{a}$ and $\mathbf{b}$ ) were defined using three points lying on the plane of the lateral ramus (Fig.6):

1. $\boldsymbol{a}=O P-O A=(\mathrm{a} 1, \mathrm{a} 2, \mathrm{a} 3)$

2. $\boldsymbol{b}=O S-O A=(b 1, b 2, b 3)$

Next the normal $(\boldsymbol{n})$ to this plane was calculated by taking the cross product of the two vectors (Fig.7). This was then normalised to produce a unit vector (vector with a magnitude of 1$)$.

3. $\boldsymbol{n}=\boldsymbol{a} \times \boldsymbol{b}=(a 2 b 3-a 3 b 2, a 3 b 1-a 1 b 3, a 1 b 2-a 2 b 1)$

4. $\widehat{\boldsymbol{n}}=\frac{\boldsymbol{n}}{|\boldsymbol{n}|}$

Having formed the plane a fourth point was then considered: Lingula/Antilingula/Mandibular Foramen. The aim was to repeat the following steps for each point in turn in order to find the position of each point on the plane of the lateral ramus. To do this a vector (c) from the Anterior Curvature to the Fourth Point was calculated using the following equation where $F$ represents the Fourth Point.

\section{5. $c=O F-O A$}

The dot product rule was then utilised to find the magnitude of this vector $(h)$ in the direction of the normal (Fig.8). This represents the height of the point above the plane.

6. $h=\boldsymbol{c} \cdot \widehat{\boldsymbol{n}}=c 1 \hat{n} 1+c 2 \hat{n} 2+c 3 \hat{n} 3$

The Fourth Point was then projected onto the plane leaving us with a vector ( $x$ ) from the Anterior Curvature to the Fourth Point. This was equivalent to the 3D coordinates of the Fourth Point on the plane relative to the Anterior Curvature (Fig.9) and was elicited by the following equation: 
7. $\boldsymbol{x}=O F-h \widehat{\boldsymbol{n}}$

Having projected the Fourth Point onto the plane the horizontal and vertical distances of $\boldsymbol{x}$ from the new origin were then calculated. To do this the horizontal axis was set as the line between the Anterior Curvature and Posterior Curvature and the vertical axis as a line perpendicular to the horizontal axis on the plane of the lateral ramus (Fig. 10).

To calculate the horizontal distance it was first necessary to normalise the horizontal vector (a).
8. $\widehat{\boldsymbol{a}}=\frac{\boldsymbol{a}}{|\boldsymbol{a}|}$

The horizontal distance was then found by the following equation (Fig.10):

\section{HorizontalDistance $=\boldsymbol{x} \cdot \widehat{\boldsymbol{a}}$}

To calculate the length of the vertical component it was first necessary to find the unit vector defining the vertical axis (v) (Fig.11).

10. $\widehat{v}=\widehat{n} \times \widehat{a}$

The vertical distance was then found by the following equation (Fig.10):

\section{VerticalDistance $=\boldsymbol{x} \cdot \widehat{\boldsymbol{v}}$}

Repeating this process for the Antilingula, Lingula and Mandibular Foramen gave the horizontal and vertical distances of each point from the Anterior Curvature on the plane of the lateral ramus. The horizontal distance of the Midwaist Point from the Anterior Curvature was easily calculated by finding half the Euclidean distance between the points of the Anterior Curvature and Posterior Curvature. The vertical distance was obviously, in each case, zero.

The calculation to find the distances of each point relative to the Anterior Curvature was automated by using a script coded in MATLAB 2015b (MathWorks Inc., Natick, USA) to facilitate rapid processing of the results. The script read from an excel sheet titled "skulldata.csv" in order to acquire the raw data for the points: Anterior Curvature, Posterior Curvature, Sigmoid Notch, Antilingula, Lingula and Mandibular Foramen. 
It then applied a function titled "function1" to four of the points. These were the three points used to define the plane (Anterior Curvature, Posterior Curvature, Sigmoid Notch) and the Fourth Point (Antilingula, Lingula, Mandibular Foramen). The process was repeated three times allowing function 1 to be applied to the Sigmoid Notch, Antilingula, Lingula and Mandibular Foramen in turn. The function applied, performed the mathematical operations on the raw data of the four sets of coordinates. The script then output the processed results into another excel sheet titled "Mandibledata.xlsx". The script was placed in an iterative loop in which each line of the excel sheet was sequentially processed from case 1 to case 480 .

The complete scripts is as follows:

1. for line $=(1: 480)$

2. SigmoidNotch $=$ csvread('skulldata.csv',(line-1),25,[(line-1) 25 (line-1) 27])' ;

3. AnteriorCurvature $=$ csvread ('skulldata.csv',(line-1),34,[(line-1) 34 (line-1) 36])' ;

4. PosteriorCurvature=csvread ('skulldata.csv',(line-1),31,[(line-1) 31 (line-1) 33])';

5. Antilingula=csvread('skulldata.csv',(line-1),28,[(line-1) 28 (line-1) 30])';

6. Lingula=csvread ('skulldata.csv',(line-1),40,[(line-1) 40 (line-1) 42])';

7. MandibularForamen=csvread ('skulldata.csv',(line-1),43,[(line-1) 43 (line-1) 45])';

8. resultLingula $=$ function1(SigmoidNotch, PosteriorCurvature, AnteriorCurvature, Lingula);

9. resultAntilingula $=$ function1(SigmoidNotch, PosteriorCurvature, AnteriorCurvature, Antilingula);

10. resultForamen $=$ function1(SigmoidNotch, PosteriorCurvature, AnteriorCurvature, MandibularForamen);

11. xIswrite('Mandibledata.xIsx',resultLingula,1,['K' num2str(line)])

12. xlswrite('Mandibledata.xlsx', resultAntilingula,1,['I' num2str(line)])

13. xlswrite('Mandibledata.xlsx', resultForamen,1,['M' num2str(line)])

14. disp(line)

15. end

The function was a separate script that was applied to the data by the main script. The script for "function1" is as follows:

1. function result $=$ function 1 (SigmoidNotch, PosteriorCurvature,AnteriorCurvature, FourthPoint)

2. $a=$ (PosteriorCurvature-AnteriorCurvature);

3. $\mathrm{b}=$ (SigmoidNotch-AnteriorCurvature);

4. $n=\operatorname{cross}(a, b)$;

5. $n=n / \operatorname{norm}(n)$;

6. $\mathrm{c}=$ FourthPoint-AnteriorCurvature;

7. $h=\operatorname{dot}(c, n)$;

8. $x=c-h * n$;

9. $a=a / n o r m(a)$;

10. HorizontalComponent $=\operatorname{dot}(x, a)$;

11. $v=\operatorname{cross}(\mathrm{n}, \mathrm{a})$;

12. VerticalComponent $=\operatorname{dot}(x, v)$;

13. result $=[$ HorizontalComponent, VerticalComponent $]$;

14. end 
Having found the coordinates of the relevant points it is then possible by simple subtraction to find the relative horizontal and vertical distances between points. This process was performed in Excel and the results graphed using Graphpad Prism 7 (Graphpad Software Inc., California, USA).

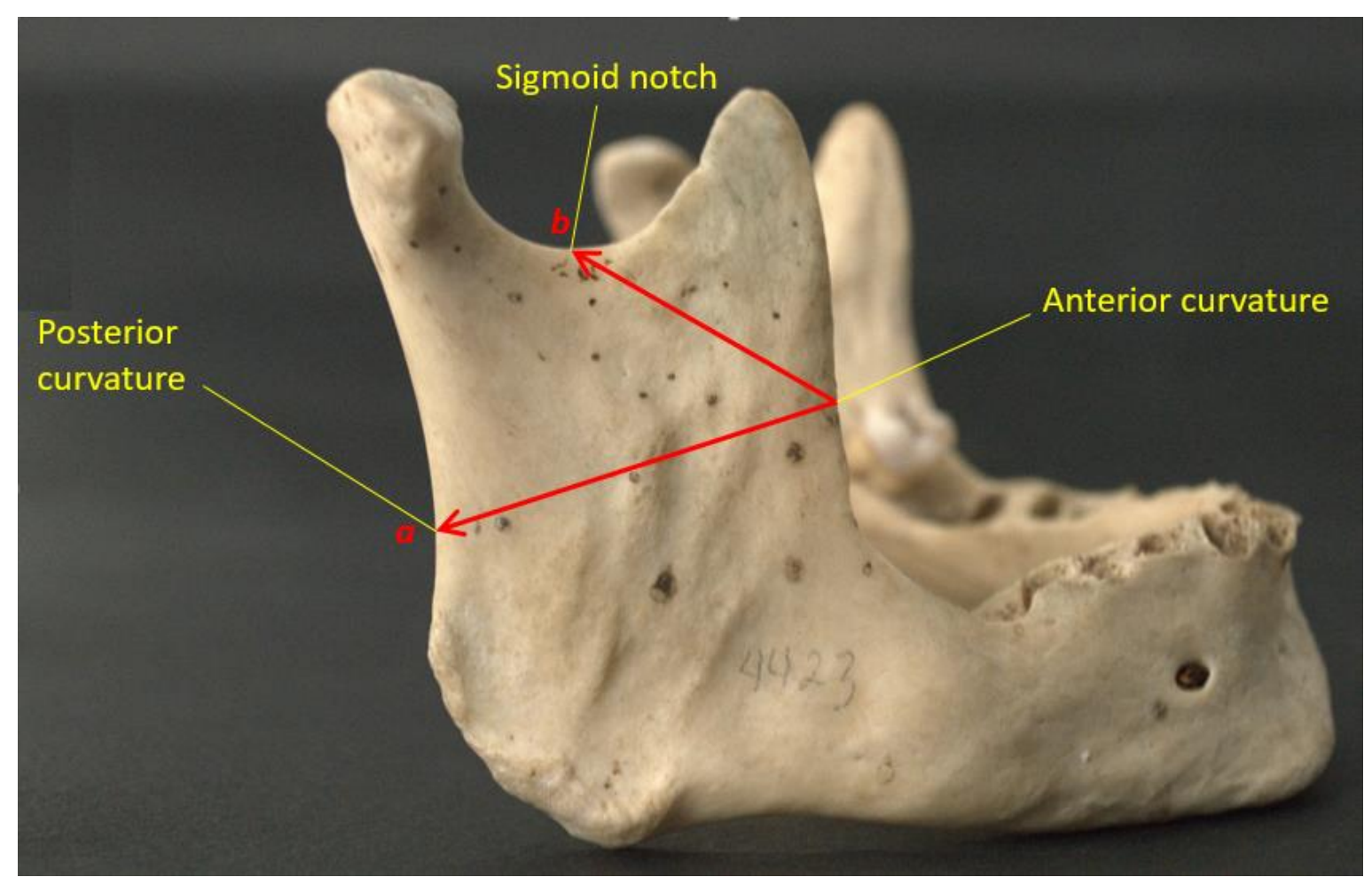

Figure 6. The anterior curvature, posterior curvature and sigmoid notch (yellow) are used to define the vectors $\boldsymbol{a}$ and $\boldsymbol{b}$. 


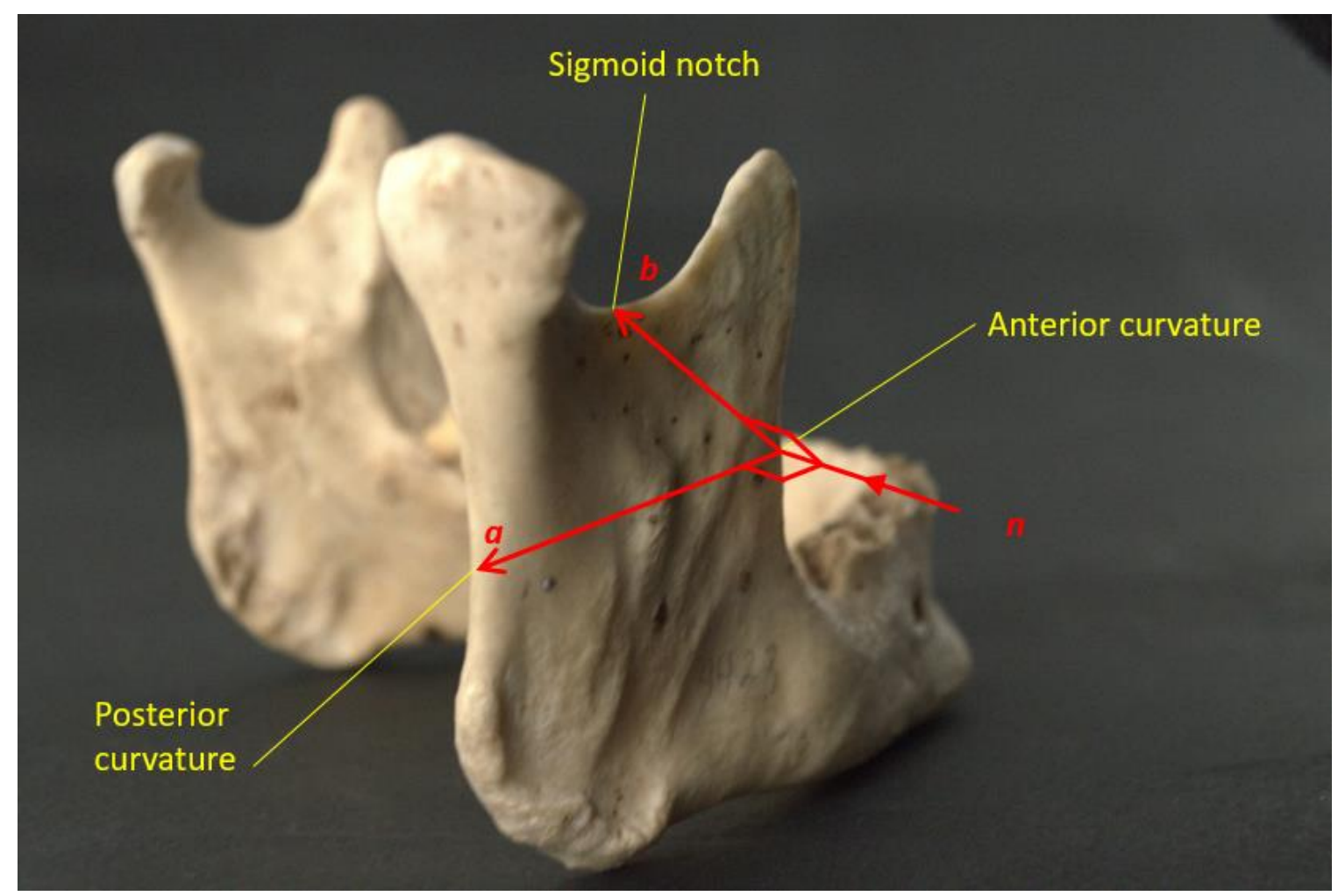

Figure 7. The cross product of vectors $\boldsymbol{a}$ and $\boldsymbol{b}$ is taken to generate vector $\boldsymbol{n}$. 


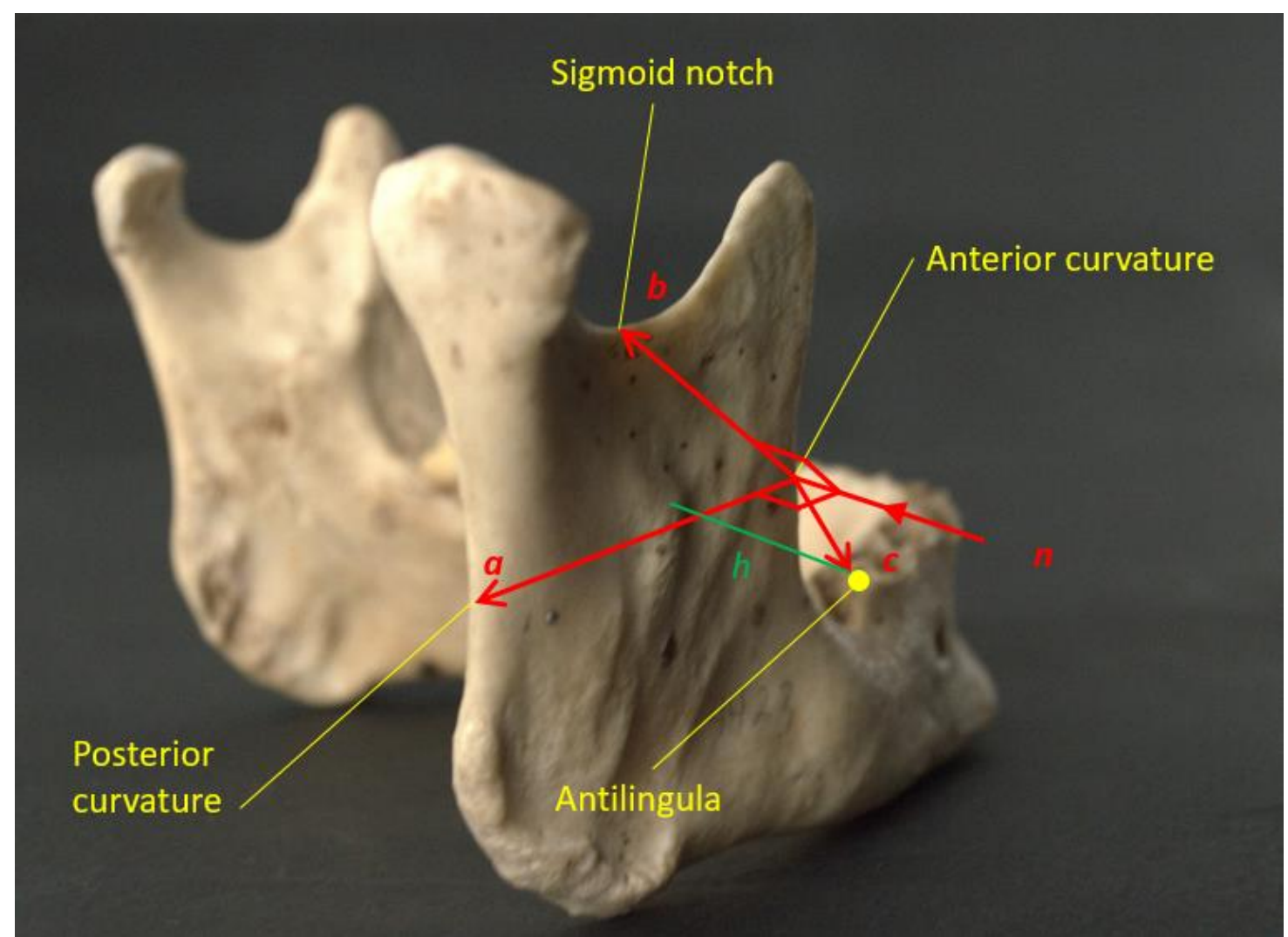

Figure 8. The fourth point in this figure is represented as a point above the plane of the lateral ramus and is marked as a yellow dot. In this example the fourth point used is the antilingula. The vector to the antilingula is denoted by the arrow labelled $\boldsymbol{c}$. the height of the point above the plane of the mandible is represented by the scalar component $h$. 


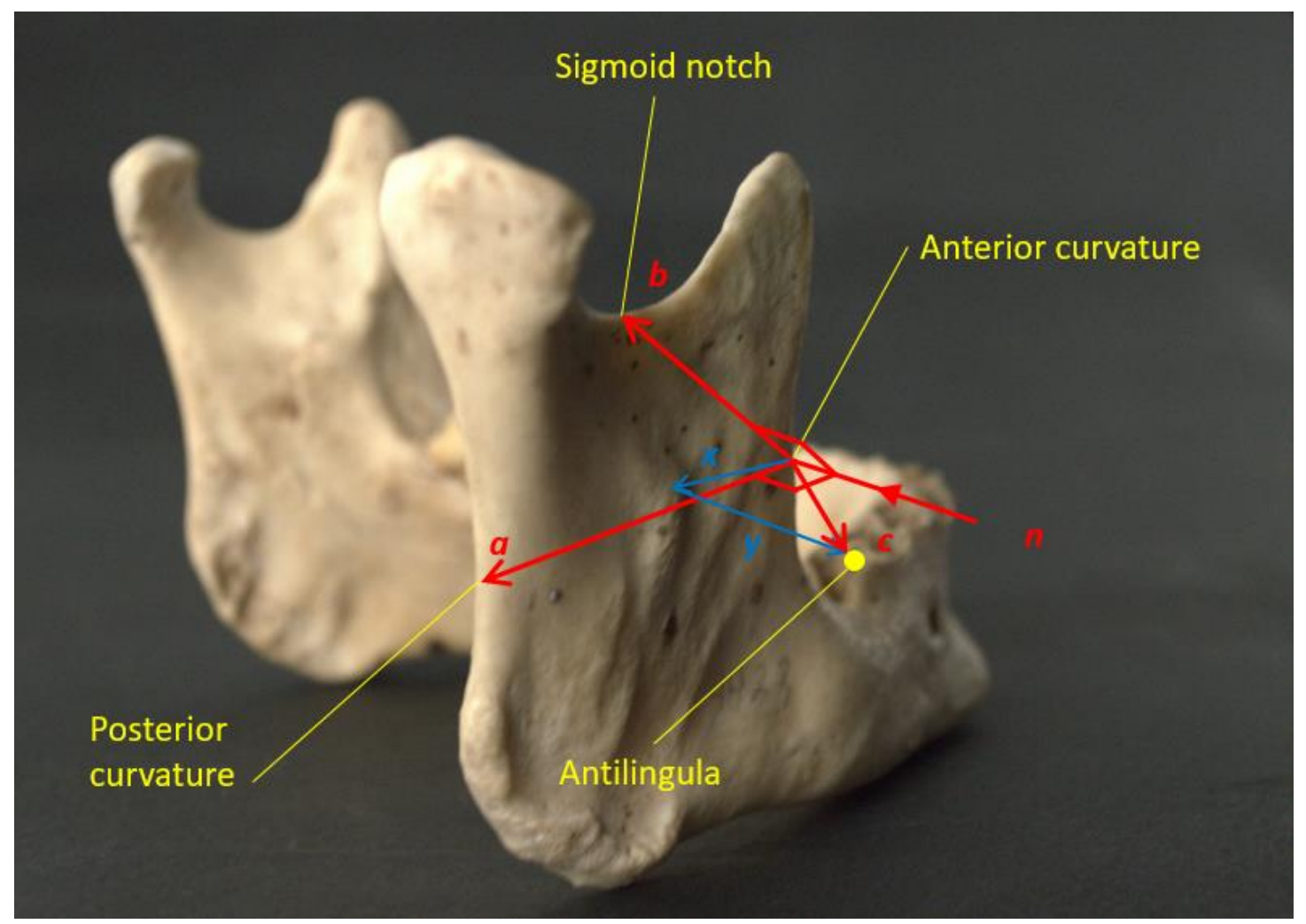

Figure 9. Vector $\boldsymbol{c}$ can be represented as the sum of the two vectors $\boldsymbol{x}$ and $\boldsymbol{y}$. Vector $\boldsymbol{y}$ is equivalent to $h \widehat{\boldsymbol{n}}$ and therefore subtracting this from $\boldsymbol{c}$ gives a projected vector of the fourth point onto the plane defined the anterior curvature, posterior curvature and sigmoid notch. 


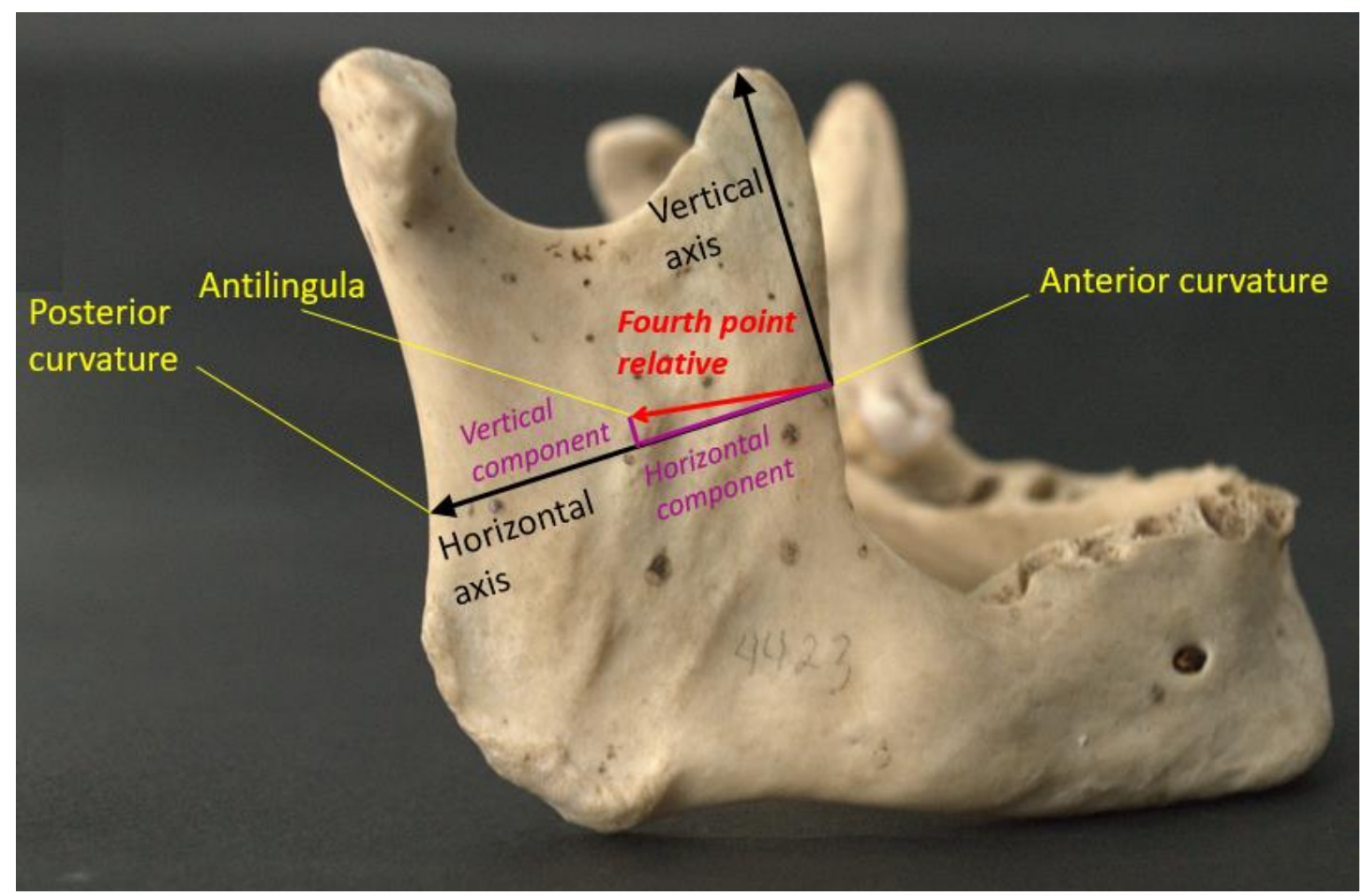

Figure 10. The horizontal axis has been set as the line connecting the Anterior Curvature to the Posterior curvature $(\boldsymbol{a})$ and the vertical axis as the line perpendicular to this in the plane of the lateral surface of the ramus. The horizontal magnitude of $\boldsymbol{x}$ may be calculated by taking the dot product relative to the unit vector $\widehat{\boldsymbol{a}}$. The vertical magnitude of $\boldsymbol{x}$ may be calculated by taking the dot product relative to the unit vector $\widehat{v}$. 


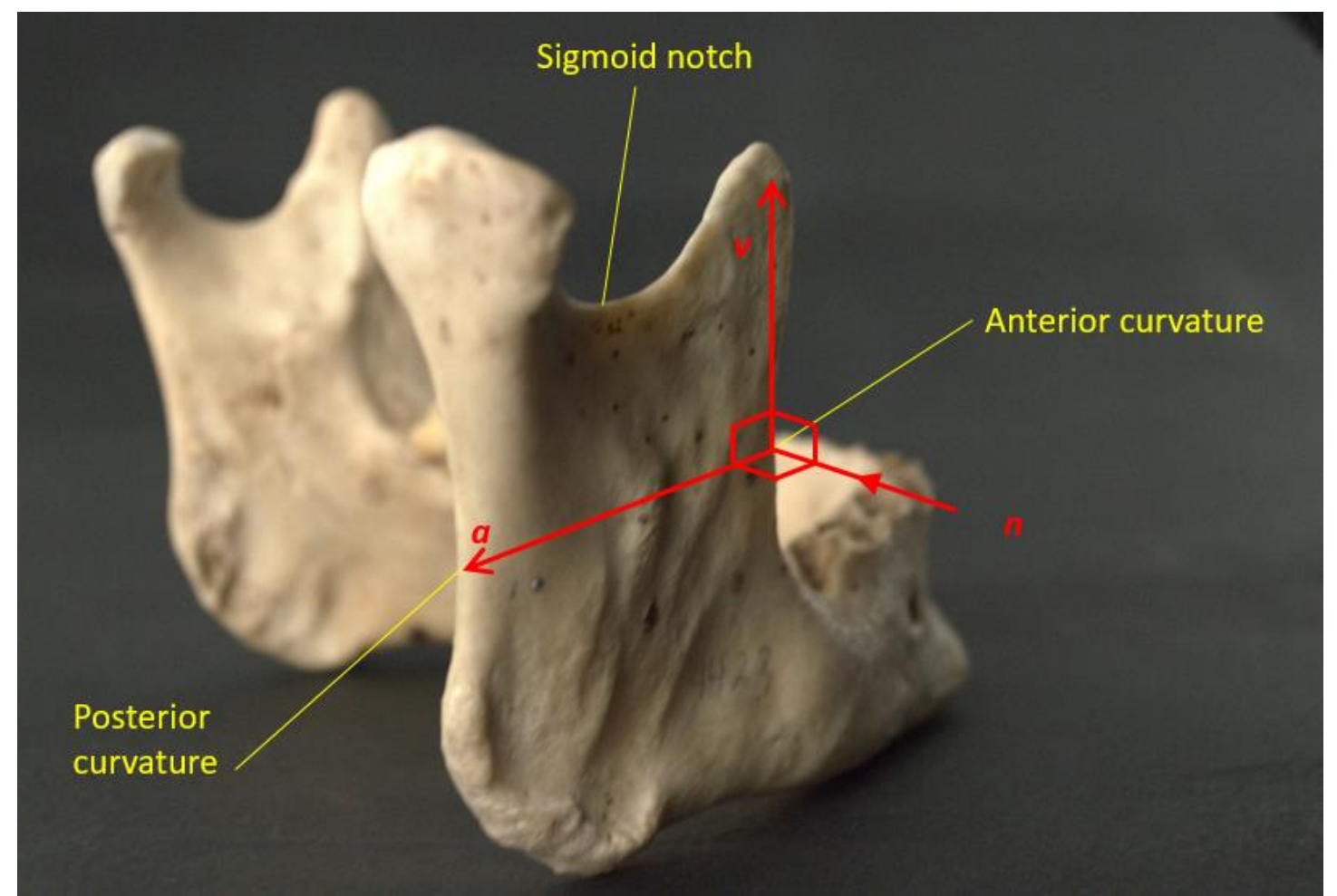

Figure 11. The vertical axis is found by taking the cross product of vectors $\boldsymbol{n}$ and $\boldsymbol{a}$. 